\title{
Application of Grey Catastrophe Theory and Microseismic Monitoring System in Early Warning for Tunnel Landslide
}

\author{
Pengfei Luo ${ }^{1, *}$, Changhong $\mathrm{Li}^{1}$ and Liu Bo ${ }^{2}$ \\ ${ }^{1}$ School of Civil and Resource Engineering, University of Science and Technology Beijing, Beijing 100083, China \\ ${ }^{2}$ City College of Dongguan University of Technology, Dongguan, China
}

Received 4 January 2021; Accepted 19 April 2021

\begin{abstract}
Early warning combined with engineering practices is necessary because landslides generally happen during expressway tunnel excavation. This study proposed a prediction method based on grey catastrophe theory and microseismic monitoring system to realize early warning for tunnel landslides. First, a microseismic monitoring system was installed in the excavated tunnel. Data on the precursory signal of surrounding rock instability such as micro-fracture and deformation caused by tunnel excavation were collected and preliminarily predicted according to the grey theory. Hence, a grey catastrophe prediction model was established to predict the occurrence of disasters. Second, the monitored precursory earthquake source points of instability and damage such as tunnel surrounding rock rupture and deformation were determined according to the basic principle of microseismic monitoring and positioning. Possible locations where disasters could happen were then predicted. Results demonstrate that the predicted landslide time and location of an expressway tunnel are close to the actual situation, and the system can realize accurate warning for tunnel landslides. This study provides a reference for real-time landslide prediction in tunnel excavation.
\end{abstract}

Keywords: tunnel, landslide, microseism, grey theory, catastrophe theory, early warning

\section{Introduction}

Landslides often happen in tunnel construction and seriously affect construction safety and progress or even lead to injury or death. Therefore, landslide prediction and warning is of great importance. Many uncertain factors lead to landslide. Despite strict management and safeguard measures, the inaccurate prediction of time and location can prompt this phenomenon. Tunnel landslide is a complex, highly nonlinear scientific problem that usually has the characteristics of large displacement, non-uniformity, and nonlinearity. The development of tunnel landslide is mainly manifested by the displacement, stress, strain, energy, and acoustic emission of surrounding rocks.

Numerous studies have been conducted on tunnel landslide in excavation. After deformation, the surrounding rocks are in a plastic state and thus exhibit the abovementioned nonlinear characteristics. Some complex mechanical behaviors such as bifurcation and sudden changes occur in the system [1]. The traditional mechanical method used to predict the instability of surrounding rocks cannot determine the mechanical parameters and loads and does not recognize the calculation formula and mechanical model. Hence, the prediction effect cannot meet engineering requirements[2]. The complex load path of surrounding rocks in tunnel excavation brings some difficulties to prediction. Moreover, geological conditions and rock mass occurrence in different places are unknown. Owing to this limited understanding, some parameters of surrounding rock medium and their mutual relations are inaccurate, and the understanding of fracture instability mechanism is

*E-mail address: ropengfly@163.com

ISSN: 1791-2377 @ 2021 School of Science, IHU. All rights reserved.

doi:10.25103/jestr.142.23 inconsistent. Therefore, this research field is in an uncertain state with incomplete information. The instability of tunnel surrounding rocks follows a grey process, and the microseismic event rate of surrounding rocks in the future predictable period cannot be calculated [3-6]. Therefore, a nonlinear scientific method is suitable to predict the instability of surrounding rock in tunnel excavation. Accurately predicting tunnel microseismic events during construction and determining the time and place of landslide are an urgent problem that must be solved.

In this study, a $\operatorname{GM}(1,1)$ mathematical model was established by using the grey catastrophe theory model and used to analyze actual projects under construction for the accurate prediction of the time and locations of landslides. The microseismic monitoring system based on the grey catastrophe theory was also applied to predict the time and locations of landslides induced by tunnel excavation. By combining the nonlinear theory and the advantages of microseismic system, this model can foresee the time and locations of tunnel landslides and overcome the shortcomings of the above-mentioned methods in the prediction and early warning of narrow areas. The results provide reference for accurately predicting the time of landslides during tunnel excavation.

\section{State of the art}

Many studies have been conducted on early warning for tunnel landslides, such as numerical study of mathematical model, analysis of field detection data, and comprehensive research combining theory and practice. Wang Yingchao[7] established a spatio-temporal prediction model for tunnel 
landslides based on stress transfer and grey-cooperative nonlinear theory; however, this model failed to create a prediction. Xu Chuanhua[8] explored the nonlinear stability of rock mass according to the dissipative structure theory and revealed the instability process and failure mechanism. They also proposed the analysis method and instability criterion. However, the field monitoring data were basically obtained from the typical section of the excavated tunnel. This point-to-surface method has the limitations of small measurement area in the radial direction of the tunnel and limited monitoring coverage in the axial direction. Jiang Anan, Cheng Xuejun, and Li Changhong[9-12] successfully used a nonlinear prediction model based on acoustic emission parameters. Theories are powerful tools and mathematical basis for solving complex and nonlinear problems such as disasters induced by tunnel excavation. However, no directional analysis has been conducted on microseismic event collection. Hu Jingyun[13] discussed the stability of typical large and complex mined-out areas but did not consider the tunnel after exploration. Miraç Eren[14] added the dimension of time to the grey relational analysis algorithm and used the multi-attribute decision analysis method. However, this strategy was not applied to the actual project. According to Delgado [15], the grey theory method considers the uncertainty in analysis, and its effectiveness has been verified in an actual application. Azadeh Dabbaghi[16] analyzed experts' qualitative judgments combined with the grey system theory and developed organizational strategic plans, and this study was conducted at the management level. Memon[17] combined the theories of grey system and uncertainty that did not require probability distribution or fuzzy membership function. However, practical engineering cases were not considered.

The model established by Fabozzi[18] showed that early warning system based on field threshold is the most suitable earthquake risk mitigation measure. Studies on the prediction of instability under strong earthquakes did not consider creep under microseismic conditions. Abraham Minu Treesa[19] realized early warning for tunnel landslides by using MEMS. Early warnings are published when the critical conditions of two parts of the system are exceeded. However, no study had applied this strategy for actual construction projects. Barbieri[20] believed that necessary tools should be provided in tunnel excavation, including real-time automatic monitoring system with threshold alarm combined with emergency procedures and coordinated with infrastructure owners. However, secondary analysis cannot be performed based on the theoretical model. Gómez Judit[21] implemented distributed optical fiber sensor system in a subway tunnel for structural health monitoring and compared it with the theoretical model of field structural conditions. The reliability of the early warning system was also studied, but the relationship between the establishment of grey theoretical model and microseismic events was not examined. Ahmed[22] analyzed the soil deformation caused by tunnel excavation and its influence. He believed that the main challenge for the new tunnel is to monitor and mitigate the surface disturbance that might affect the existing structure. Therefore, he conducted an analysis through field data and numerical simulation but failed to investigate the critical points of landslides. Li Shulin[23] analyzed the data of precursory focal mechanism solution combined with the microseismic moment tensor theory and judged the fracture type of engineering rock mass but failed to predict the time and place of landslide. Verdon[24] conducted a case study according to the actual situation and demonstrated how to use the L-shaped downhole fiber array to monitor microseisms. A relatively simple method was applied to detect events from continuous waveform data, and a workflow was developed. However, comprehensive analysis was not conducted in combination with the grey theory. Considering the difficulty and low accuracy in locating micro-seismic sources in the surrounding rock of deep tunnels, Wang Jianfeng[25] used heuristic algorithm-gravity search algorithm to search for micro-seismic sources in the surrounding rocks of tunnel and compared the search results from the algorithm, particle swarm optimization, and simplex method. However, the grey theory was not employed for comparative analysis.

These theories are powerful tools and mathematical basis for solving complex and nonlinear problems such as disasters induced by tunnel excavation. However, the above studies failed to use the proper method to explore the practical application of grey theory. Only a few works on disaster prediction in tunnel excavation had employed a microseismic monitoring system and applied the grey catastrophe theory. In the present study, grey theory combined with microseismic event collection was adopted to develop a calculation model for microseismic event rate. A field implementation scheme of microseismic system was also discussed. Microseismic wave velocity was collected and analyzed. A catastrophe model was also established through fitting curve and transformation to provide a basis for studying the time and place of tunnel landslides.

The remainder of this study was organized as follows. Section 3 describes the structure of the microseismic event rate model based on the grey theory, the field implementation scheme, and the determination of microseismic wave velocity. Section 4 presents how the function sequence was established based on the above model and how the prediction value and prediction error of microseismic event rate were obtained. The time of instability of surrounding rock was also determined, and the specific location was predicted. Finally, section 5 discusses the summary and conclusions.

\section{Methodology}

The microseismic event rate of surrounding rock instability precursor signals such as micro-fracture and deformation caused by tunnel excavation was calculated following the basic principle of microseismic monitoring system. A GM $(1,1)$ model of on-site monitoring data was established, and the frequency of microseismic events in the next working period of rock was predicted. Dynamic information was provided, and a model was established for data acquisition. The catastrophe model was obtained through fitting curve and transformation, and the time of disaster was predicted. Following the basic principle of microseismic monitoring and positioning, the precursory earthquake source points of rupture and deformation of tunnel surrounding rock were located. Finally, the time and location of the final disaster were predicted according to the catastrophe theory for the forecast and prevention of disasters.

\subsection{Project Overview}

The separated tunnel is a deep-buried extra-long tunnel with a left-right distance of 40 meters and a total length of 5000 meters. The maximum buried depth is over 300 meters. The tunnel section has a loose structure with poor shear strength and thus is prone to landslide. 


\subsection{Construction of grey theoretical model}

The microseismic event rate is predicted by establishing a grey theory model.

First, the microseismic event rate, which is a data series, was established based on the order of time. In time series $t_{1}, t_{2}, t_{3}, \ldots t_{n}$, the number of microseismic monitoring events is $x_{1}, x_{2}, x_{3}, \ldots x_{n}$.

Let $x^{0}=\left(x^{0}(1), x^{0}(2), x^{0}(2) \ldots x^{0}(\mathrm{n})\right.$

A simple summation sequence was randomly generated, $x^{1}$, and

$x^{1}=\left(x^{1}(1), x^{1}(2), x^{1}(2) \ldots x^{1}(\mathrm{n})\right.$

The whitening differential equation of $\operatorname{GM}(1,1)$ model is as follows:

$$
\frac{d x^{1}}{d t}+a x^{1}=1
$$

The following function sequence of $\operatorname{GM}(1,1)$ was obtained as follows:

$$
x^{0}(k)=\left(1-e^{a}\right)\left(x_{0}(1)+\frac{b}{a}\right) e^{-a(k-1)}
$$

The microseismic event rate was predicted by using equation (4) and processed into power series by curve fitting:

$$
y=a_{0}+a_{1} t+a_{2} t^{2}+a_{3} t^{3}+a_{4} t^{4}
$$

where $a_{0}, a_{1}, a_{2}, a_{3}, a_{4}$ are the coefficients to be determined, and $y$ is the microseismic event rate at $t$.

The cusp catastrophe model was obtained through differential homeomorphism transformation by transforming equation (5):

$y=x^{4}+u x^{2}+v x+c$

where,

$u=-6 p^{2}+\frac{a_{2}}{a_{4}}, v=8 p^{3}+2 p \frac{a_{2}}{a_{4}}+\frac{a_{1}}{a_{4}}, p=\frac{a_{3}}{4 a_{4}}$

where $x$ is state variable, and $\mathrm{u}$ and $\mathrm{v}$ are control variables. The important parameters were determined. For microseismic monitoring and prediction, $y$ is the microseismic event rate of microseismic monitoring; $x$ is the mechanical parameter of the mechanical process, $u$ and $v$ reflect the parameters related to the mechanical process and microseismic monitoring, respectively; and $c$ is a constant. Equation (6) was derived to obtain the equilibrium surface equation:

$$
4 x^{3}+2 u x+v=0
$$

In Equation (7), the relationship equilibrium surface between state variable $\mathrm{x}$ and control variables $\mathrm{u}$ and $\mathrm{v}$ is a singular point set, and the control variable surface is a bifurcation set. The equation is as follows:

$8 u^{3}+27 v^{3}=0$

$x$ changes steadily with the constant changes of two parameters $u$ and $v$ in the control variable plane. When the control point crosses the bifurcation point set, $x$ is bound to jump suddenly. The judgment criterion was expressed as below:

$$
F=8 u^{3}+27 v^{2}
$$

When $F>0$, the rock mass is stable. When $F=0$, it is in a critical state. When $F<0$, the rock mass is unstable.

\subsection{Field implementation of microseismic system}

Rock mass data were collected by using BMS high-precision microseismic monitoring system to determine the inelastic deformation, released energy, and time parameters of microfracture. Figure 1 shows that when the surrounding rocks were damaged, the released energy triggered the embedded geophone with elastic waves. Owing to the difference in the distance between the seismic source and the geophone, the time when the seismic wave propagates to the geophone also varied. Seismic source location and energy calculation were conducted according to the time difference for each geophone.

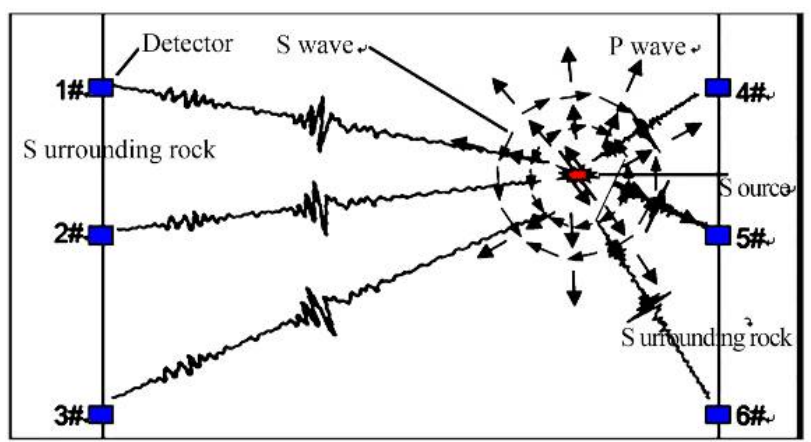

Fig. 1. Schematic of microseismic monitoring

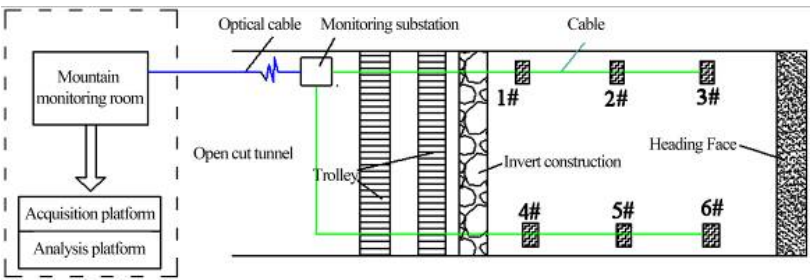

Fig. 2. Schematic of field layout

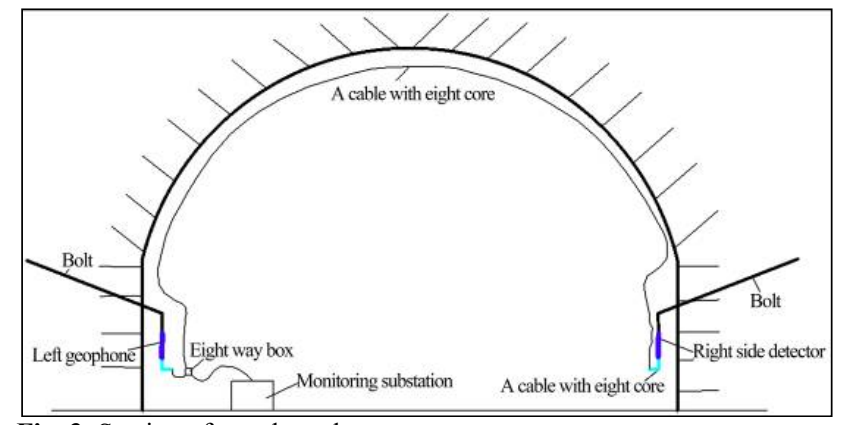

Fig. 3. Section of geophone layout

Microseismic monitoring is rarely used in tunnel construction. Hence, the proposed system for tunnel 
excavation combining the characteristics of tunnel construction technology and microseismic technology must be implemented gradually. Considering the characteristics of tunnel construction, the left and right lines were constructed separately. The monitoring substation was installed on the right line of the tunnel and was moved forward with the advance of the working face. During the monitoring of the right-line tunnel, the monitoring substation continuously records the disturbance caused by the excavation of the leftline tunnel and the rock mass around the geophone for 24 hours to ensure the safety of tunnel construction. The layout area spanned from the face to the second lining (Fig.2), and the sensors were mechanically arranged. The distance between the monitoring points was $15 \mathrm{~m}$ to $20 \mathrm{~m}$, and the geophone was arranged on the primary lining (Fig.3).

\subsection{Determination of microseismic wave velocity}

Microseismic wave velocity was determined through blasting calibration. The calibration method is as follows. When blasting occurs, microseismic events are automatically collected by the microseismic system, and the arrival time of the corresponding geophones can be obtained through analysis. The spatial coordinates of blasting source and each geophone were measured with instruments. Given the time and distance, time difference, and distance difference between each monitoring point and the seismic source, the values can be solved by using simultaneous equations. Therefore, the propagation velocity of the microseismic waves in the rock mass can be obtained. Mean value was calculated by screening multiple groups of wave velocities. The waveform was collected manually, and the arrival time of microseismic wave at each monitoring point was obtained as shown in Table 1.

Table 1. Time summary of the vibration waves produced by blasting

\begin{tabular}{|c|c|c|c|c|}
\hline \multirow[b]{2}{*}{$\begin{array}{l}\text { Monitoring } \\
\text { points }\end{array}$} & \multicolumn{3}{|c|}{ Geophone coordinates } & \multirow[b]{2}{*}{$\begin{array}{l}\text { Arrival } \\
\text { time }\end{array}$} \\
\hline & $\begin{array}{l}\text { Coordinate } \\
\text { of axis X }\end{array}$ & $\begin{array}{l}\text { Coordinate } \\
\text { of axis Y }\end{array}$ & $\begin{array}{l}\text { Coordinate } \\
\text { of axis } Z\end{array}$ & \\
\hline $2 \#$ & 208.6199 & 154.9804 & 3.1 & 1027 \\
\hline $3 \#$ & 184.6127 & 142.6259 & 3 & 1015 \\
\hline 4\# & 197.9913 & 149.4096 & 2.1 & 1017 \\
\hline $7 \#$ & 217.2245 & 145.671 & 3.3 & 1019 \\
\hline $8 \#$ & 189.2063 & 131.4952 & 3.5 & 1024 \\
\hline 9\# & 204.3691 & 139.1829 & 2.5 & 1019 \\
\hline $\begin{array}{l}\text { Blasting } \\
\text { source }\end{array}$ & 121.6081 & 57.5003 & 8.1 & 0 \\
\hline
\end{tabular}

Average values were obtained, and the wave velocity was $4.561 \mathrm{~m} / \mathrm{ms}$.

\section{Results and Discussion}

\subsection{Prediction of disaster time}

With the above theoretical model, the tunnel construction process can be dynamically monitored in a large area to predict the microseismic event rate. The values of $a$ and $b$ were obtained by the least square method and the extreme value (see Table 2).

The first-order whitening nonlinear differential equation of $\operatorname{GM}(1,1)$ model is as follows:

$$
\frac{d x_{1}}{d t}-0.4669 x_{1}=0.0173
$$

The time response function sequence of $\operatorname{GM}(1,1)$ model is as follows:

$$
x_{0}(k)=1.1052 e^{0.4669(k-1)}
$$

The predicted value and error of microseismic event rate were calculated and are shown in Table 2.

Table 2. Measurement and prediction of microseismic events

\begin{tabular}{l|l|l|l|l}
\hline \multirow{2}{*}{$\begin{array}{l}\text { Time } \\
\text { series }\end{array}$} & \multirow{2}{*}{ Date } & \multicolumn{2}{|l|}{$\begin{array}{l}\text { Microseismic event } \\
\text { rate }\end{array}$} & $\begin{array}{l}\text { Predicti } \\
\text { on error } \\
\text { (\%) }\end{array}$ \\
\cline { 3 - 4 } & & $\begin{array}{l}\text { Measure } \\
\text { value }\end{array}$ & $\begin{array}{l}\text { GM } \\
\text { Predicte } \\
\text { d value }\end{array}$ & \\
\hline 1 & November 2nd & 3 & 3.00 & 0.00 \\
2 & November 3rd & 2 & 1.81 & -9.64 \\
3 & November 4th & 4 & 2.88 & -27.94 \\
4 & November 5th & 7 & 4.60 & -34.32 \\
5 & November 6th & 5 & 7.33 & 46.67 \\
6 & November 7th & 15 & 11.70 & -22.02 \\
7 & November 8th & & 18.66 & \\
8 & November 9th & & 29.76 & \\
9 & November 10th & & 47.47 & \\
\hline
\end{tabular}

A curve was drawn and is shown in Fig. 4.

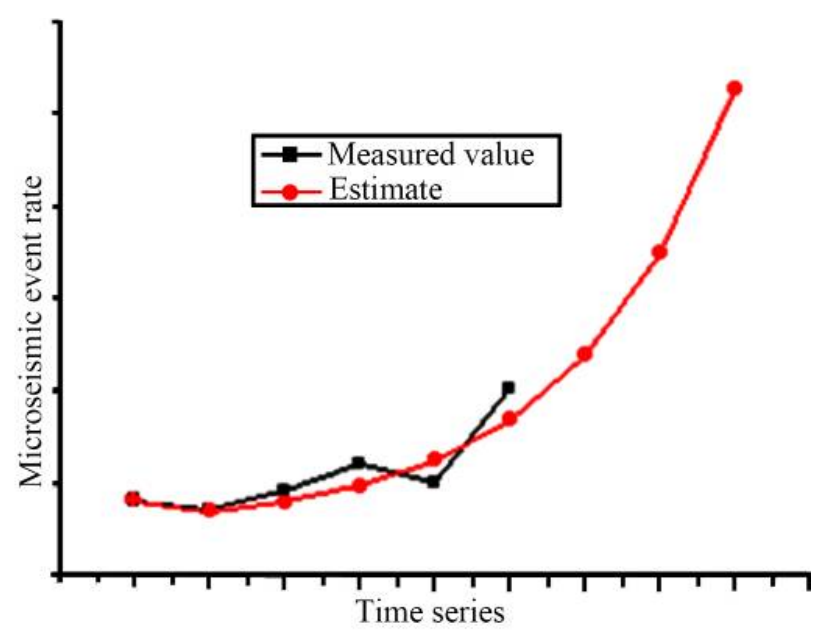

Fig. 4. Comparison of monitoring and prediction data

The 7th, 8 th, and 9th predicted values were substituted to the mutation model, and $a_{i}$ was calculated using the least square method to obtain $\mathrm{u}, \mathrm{v}$, and $\mathrm{F}$. Table 3 lists the prediction values for 3 continuous days.

Table 3. Prediction results of tunnel landslide

\begin{tabular}{l|l|l|l|l|l}
\hline $\begin{array}{c}\text { Time } \\
\text { series }\end{array}$ & \multicolumn{1}{|c|}{ Date } & \multicolumn{1}{|c|}{$\mathbf{u}$} & $\mathbf{v}$ & \multicolumn{1}{|c|}{ F } & $\begin{array}{l}\text { Whether } \\
\text { landslide } \\
\text { happens }\end{array}$ \\
\hline 9 & November $8^{\text {th }}$ & 2.28 & 4.94 & 1107.322 & NO \\
10 & $\begin{array}{l}\text { November } 9^{\text {th }} \\
10\end{array}$ & 3.70 & 5.07 & 1242.07 & NO \\
11 & $\begin{array}{l}\text { November } \\
10^{\text {th }}\end{array}$ & -2.55 & -3.43 & -147.206 & YES \\
\hline
\end{tabular}

The calculation results revealed that on November 10, $\mathrm{F}<0$, a landslide will happen on the surrounding rock of the tunnel. This prediction is close to the actual tunnel landslide at 21:53 on November 10, 2011.

\subsection{Prediction of disaster location}

In tunnel construction, microseismic events have the same frequency as the surrounding rock movement, that is, the distribution area coincides with the movement field and the 
high stress difference area of the surrounding rock. The precursory microseismic event rate of the surrounding rock instability of the tunnel was predicted by using the grey catastrophe theory model, and the occurrence time of the surrounding rock instability was also obtained. In this part, the precursory microseismic events were located, and the place where the surrounding rock failure and instability will happen was predicted. The positioning results from the data analysis of surrounding rock fracture event from November 1, 2011 to November 8, 2011 are shown in Fig. 5.

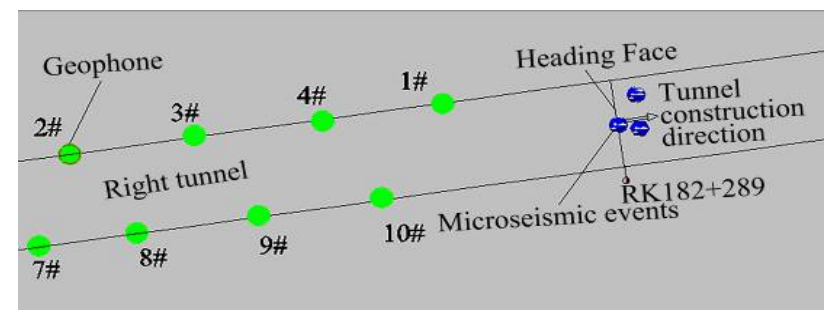

(a)November 2, 2011

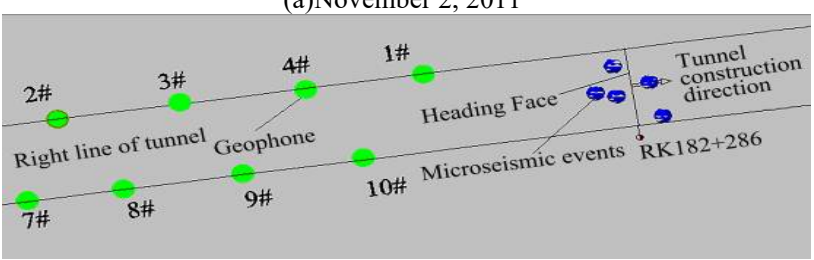

(b)November 3, 2011

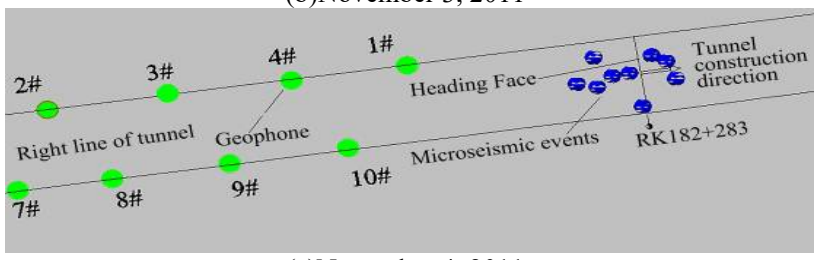

(c)November 4, 2011

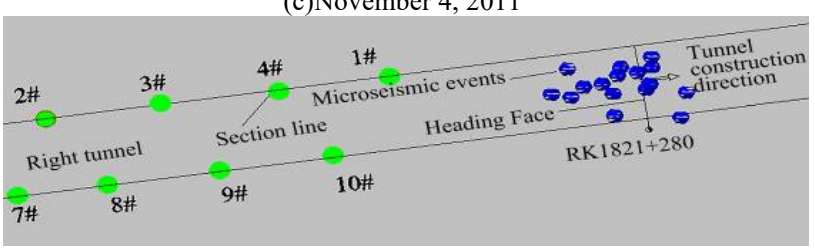

(d)November 5, 2011

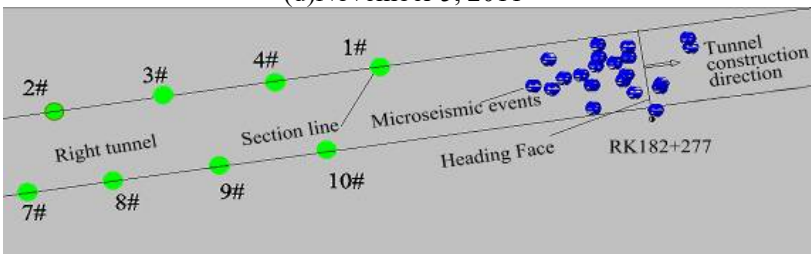

(e)November 6, 2011

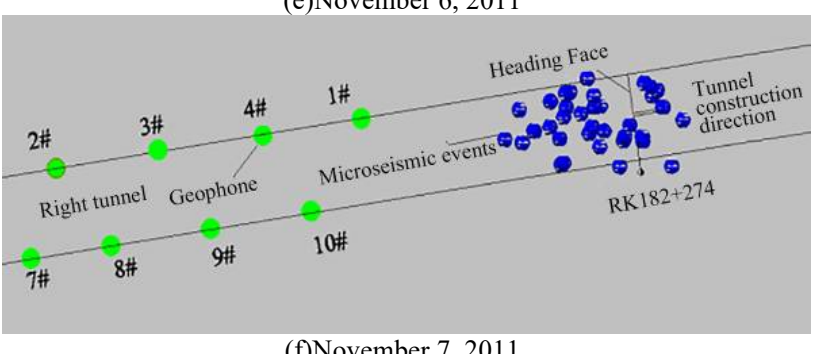

(f)November 7, 2011

Fig. 5.Schematic of cumulative microseismic event rate

According to the above monitored microseismic events, the microseismic rupture and deformation events were mainly concentrated at the tunnel exit RK182+268 RK182 290. With the advancement of the heading face, the microseismic event rate showed an increasing trend. The grey catastrophe model of microseismic event rate was also analyzed, and the time of landslide was predicted. On the basis of the spatial distribution characteristics of microseismic events, the surrounding rock landslide induced by tunnel excavation was predicted to be mainly distributed at RK182+268 RK182 290. At 21:53 on November 10, 2011, the right line of the tunnel of LJ4 contract section of an expressway was constructed to RK182+267.6. The tunnel collapsed, the primary support at the upper step $\mathrm{K} 182+287 \sim \mathrm{K} 182+267.6(19.4 \mathrm{~m})$ and the left side of the lower step K182+282.6 K182+287 (4.4 m) also collapsed, and roof failure was formed.

This finding is in good agreement with the location of landslide analyzed by the microseismic monitoring system. Many gullies and fissures were found on the surface of the tunnel, which crossed a fold. Stress concentration resulted in rock stratum breakage and joint development at the fold axis and inflection point of both wings, which is also the dominant position of fault development. This phenomenon influenced the stability of the engineered tunnel.

\section{Conclusions}

Tunnel excavation was monitored by using a microseismic monitoring system to accurately predict the time and location of landslides. The monitoring data were predicted according to the grey catastrophe theory model. The following conclusions could be drawn:

(1) The microseismic event rate comprehensively reflects the deformation and fracture of the surrounding rock system of the tunnel, and its size indicates the damage degree of rock medium. A grey catastrophe theory model is established to predict the development trend of surrounding rocks.

(2) During construction, the microseismic events have the same frequency as the surrounding rock movement. Hence, the movement of the surrounding rocks can be predicted according to the microseismic events.

(3) On the basis of the microseismic event rate monitored by the microseismic system, a grey catastrophe model is successfully established to effectively predict the occurrence time of tunnel landslides. According to the principle of microseismic monitoring and positioning, the location of landslide can be accurately predicted.

(4) The microseismic monitoring system can monitor the disasters induced by tunnel excavation in a wide area and with high precision. This innovation advances the development direction of tunnel disaster monitoring.

On the basis of field monitoring and theoretical study, the method of combined grey catastrophe theory and strong earthquake monitoring system was proposed. The established prediction model is simplified and close to field reality and thus can accurately determine the time and location of landslides and provide reference for predicting disasters induced by tunnel excavation.

\section{Acknowledgements}

This work was supported by the National key research and development program of the 13th five year plan (Subject No.2017YFC0804609).

This is an Open Access article distributed under the terms of the Creative Commons Attribution License. 


\section{References}

1. Xie,H., Liu,X., Wang,J., "Thoughts on the development strategy of rock mechanics in the 21 st century". Journal of Geotechnical Engineering, 18(4),1996, pp.101-105.

2. Zheng,Y., Liu,X., "Modern nonlinear science and rock mechanics". Journal of geotechnical engineering,18(1) ,1996, pp. 98-100.

3. Xu,Z., Xu,X., "Seismic cusp catastrophe model considering rheological properties of surrounding rock". Geotechnical Mechanics, 21(1),2000, pp.24-27.

4. Xu,C., Ren,Q., "Entropy catastrophe criterion for stability analysis of surrounding rock". Geotechnical Mechanics ,25(03),2004,pp.437440 .

5. Ma,S., Xiao,M.,Wang,J.,"Prediction of surrounding rock deformation of underground powerhouse based on Chaotic RBF neural network". Journal of Wuhan University (Engineering Edition) ,42 (2), 2009,pp. 205-208.

6. Tan,G.,Dong,X.,YIN,X., "The predictive model of the tunnel collapse height based on BP artificial neural network and multiple regression" .Journal of Mountain Science,21(4),2003,pp.507-510.

7. Wang,Y.,Shang,Y.,Xu,X., "Time and space prediction of collapse of loose wall rock at tunnel exit ".Chinese Journal of Geotechnical Engineering,32(12),2010,pp.1868-1874.

8. Xu,J., "Research on grey-cusp-catastrophic destabilization prediction model of tunnel surrounding rock and primary support system". Chinese Journal of Rock Mechanics and Engineering,7(6),2002,pp.11811187.

9. Jiang,A., "Forcasting nonlinear time series of surrounding rock deformations of undergrounding cavern based on PSO-SVM".Rock and Soil Mechanics,8(6),2007,pp.1176-1180.

10. Cheng,X.,Hu,W.,Cai,M., “Application of AE technique and nonliear theory on forcasting the rock masses falling".Journal of University of Science and Technology Beijing,20(5),1998,pp.409-411.

11. Li,C.,Zhang,L.,Zhang,L., "Application of grey catastrophe theory and acoustic emission in rock burst prediction".China Mining Magazine, 17 (8),2008,pp.87-90.

12. Tian,Q.,Fu,H., "Failure Time Prediction of Slope Collapse of Blcok Rockmass Based on Gray and Catastrophic Theories".Journal of South China University of Technology, 37 (12),2009,pp.122-126.

13. Hu,J., "Research of Theory and Application of Microseisimic Monitoring Technology on Large Complex Gob Stability". Master thesis of Changsha Institute of Mining Research, 5,2011.

14. Miraç,E., Selahattin,K., "An evaluation of EU member states according to human development and global competitiveness dimensions using the multi-period grey relational analysis (MP-GRA) technique". Grey Systems: Theory and Application, 7(1), 2017,pp.6070
15. Delgado, A., Ayala, B., "Analysis from point of the view parents on mathematics learning using the grey systems theory". In: 2019 IEEE World Conference on Engineering Education (EDUNINE). New York, USA: IEEE, 2019, p. 1-5..

16. Dabbaghi, A., Maryam,D., "Determining the Most Important Components of the Petroleum Corporate Mission Statement Using Grey Systems Theory”. Petroleum Business Review ,3(2).2019,pp.4354.

17. Memon, M. S., Young H. L., and Sonia I. M.. "Group multi-criteria supplier selection using combined grey systems theory and uncertainty theory". Expert Systems with Applications, 42(21), 2015,pp. 7951-7959.

18. Fabozzi, S., "Feasibility study of a loss-driven earthquake early warning and rapid response systems for tunnels of the Italian highspeed railway network". Soil Dynamics and Earthquake Engineering,112,2018,pp.232-242.

19. Abraham, M. T. , Satyam, N. , Bulzinetti, M. A. , Pradhan, B. , \& Segoni, S. . "Using Field-Based Monitoring to Enhance the Performance of Rainfall Thresholds for Landslide Warning". Water ,12 (12).2020,pp.3453-3453.

20. Barbieri, G., Giani, M., Kündig, M., \& Motta, S. , "The use of real time monitoring systems to reduce execution risks during tunnel excavation in complex situations: The case of Stalvedro tunnel, Switzerland". Tunnels and Underground Cities: Engineering and Innovation meet Archaeology, Architecture and Art. CRC Press, 2019. 626-635.

21. Gómez, J., Joan R. C., .Sergi,V., "Structural Health Monitoring with Distributed Optical Fiber Sensors of tunnel lining affected by nearby construction activity". Automation in Construction,117,2020,pp. 103261.

22. Ahmed, N. Z., El-Shourbagy, M., Akl, A., \& Metwally, K., "Field monitoring and numerical analysis of ground deformation induced by tunnelling beneath an existing tunnel". Cogent Engineering ,8(1),2021,pp. 1861731.

23. Li,S., Lin, K., Zhou,M., Zhang,J., Hong,Y., Hu,J., Peng,F., "Study on the mechanism of earthquake preparation before the failure of super large mountain based on moment tensor analysi". Journal of rock mechanics and engineering, 38 (10),2019,pp.2000-2009

24. Verdon, J. P., Horne, S. A., Clarke, A., Stork, A. L., Baird, A. F., \& Kendall, J. M. "Microseismic monitoring using a fiber-optic distributed acoustic sensor array". Geophysics, 85(3),2020,pp.89-99.

25. Wang, J., Li,T., Ma,C., Zhang,h., Han,X., Zhou,X., Jiang,Y., "Study on microseismic location of tunnel surrounding rock based on gravitational search method". Geotechnical mechanics, 40(11), 2019,pp. 4421-4428+4476. 